\title{
An unusual unilateral benign congenital anomaly of the pupil
}

\author{
Chandrasekharan Rajasekharan, ${ }^{1}$ Varghese Attumalil Thomas, ${ }^{1}$ \\ Rajasekharan Gayathry, ${ }^{2}$ Rajasekharan Parvathy ${ }^{3}$
}

${ }^{1}$ Department of Internal Medicine, Medical College Hospital, Thiruvananthapuram, Kerala, India

${ }^{2}$ Department of Internal Medicine, Cochin Medical College, Eranakulam, Kerala, India

${ }^{3}$ Department of Internal Medicine, M.O.S.C. Medical College, Eranakulam, Kerala, India

\section{Correspondence to} Professor Chandrasekharan Rajasekharan,

drcrajasekharan@yahoo.com

Accepted 12 May 2014

\section{DESCRIPTION}

A 50-year-old male manual labourer attended the outpatient department with history and clinical features of upper respiratory infection. He had studied up to the fifth grade. There was no history of visual symptoms. There was no significant family history of congenital ocular diseases. His vital signs, general and system examinations were normal. However, examination of his left eye showed a

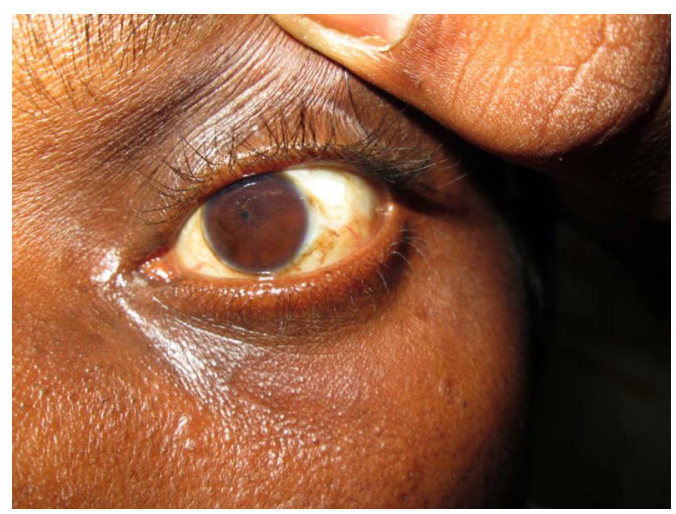

Figure 1 Pupil of the left eye is small in size, displaced nasally and inferiorly suggestive of corectopia. small eccentrically placed pupil with reduced papillary diameter (figure 1). The right pupil was of normal size and reaction (figure 2). The comparative images of both eyes are shown in (figure 3A, B, C). The extraocular movements were normal and full bilaterally. His visual acuity and optic fundi were normal. An ophthalmic consultation was done, which demonstrated a normal visual field and acuity. $\mathrm{He}$ was diagnosed as having unilateral idiopathic tractional corectopia. Congenital abnormalities of pupil position and shapes are uncommon. The normal pupil sizes in adults vary from 2 to $4 \mathrm{~mm}$ in diameter in bright light to $4-8 \mathrm{~mm}$ in the dark and are generally equal in size. ${ }^{1}$ Pupils are normally situated about $0.5 \mathrm{~mm}$ inferonasally from the centre of the iris. ${ }^{2}$ Corectopia refers to displacement of the pupil, which is normally situated about $0.5 \mathrm{~mm}$ inferonasally from the centre of the iris. Minor deviations of up to $1 \mathrm{~mm}$ are usually cosmetically insignificant and should probably not be considered abnormal. $^{2}$ In this case, the abnormal position of the pupil is caused by a fibrous structure that tethers the iris pupillary margin to the peripheral cornea. ${ }^{3}$ Idiopathic tractional corectopia is an isolated unilateral congenital pupil abnormality with a highly characteristic appearance.

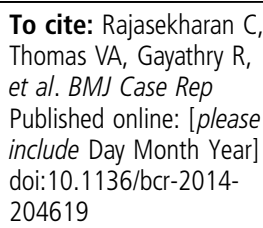

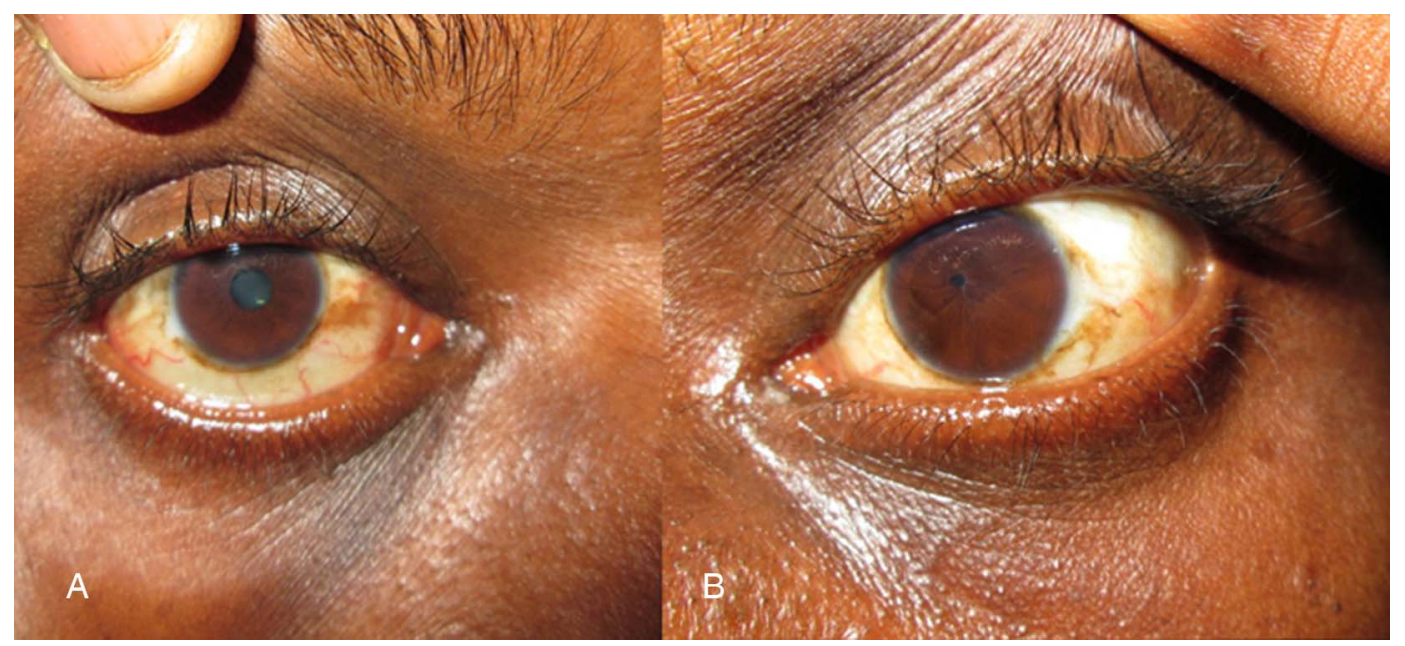

Figure 2 Images of the two eyes shown together for comparison. (A) Normal pupil of the right eye. (B) Pupil of the left eye is small in size, displaced nasally and inferiorly suggestive of corectopia. 


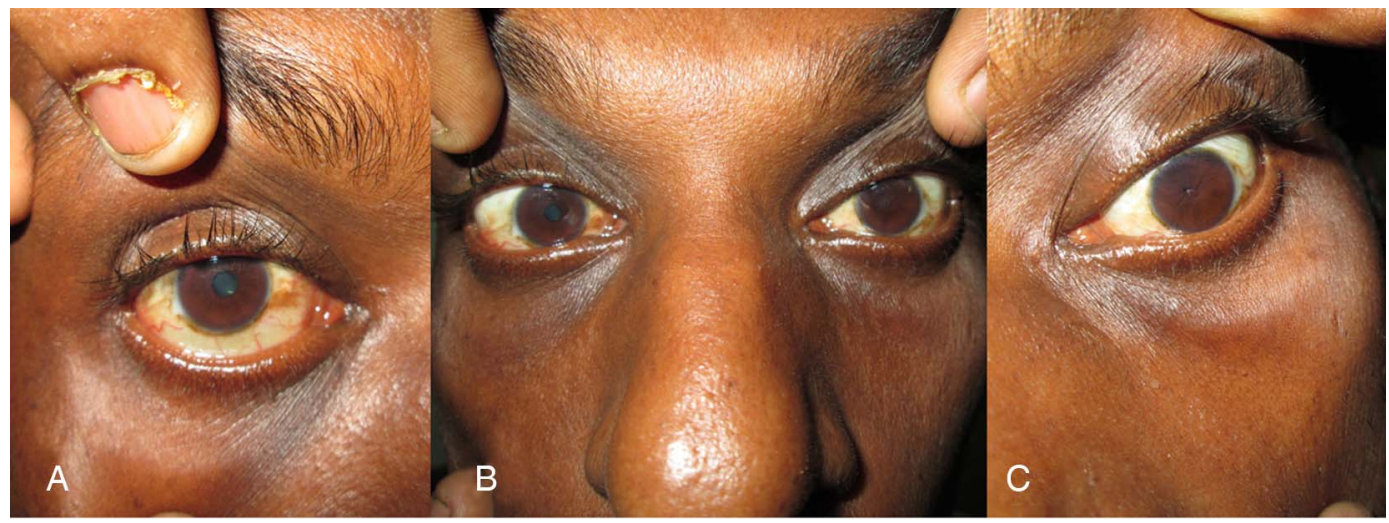

Figure 3 (A) Normal pupil on the right side. (B) Photograph of both eyes taken together showing corectopia on the left and normal pupil on the right. (C) Left eye showing corectopia.

\section{Learning points}

- Anisocoria in young patients is most frequently physiological (benign) and is present in approximately $20 \%$ of healthy patients.

- In this rare anomaly, visual acuity may be good, even with eccentric pupils, if not associated with other congenital anomalies or defective vision; only reassurance is needed. Most cases require no intervention or respond well to simple lysis of the fibrous strand that is characteristic of the condition.

- Differential diagnosis of corectopia includes iridocorneal endothelial syndrome, Axenfeld-Rieger syndrome, trauma, sector iris hypoplasia or other colobomatous lesions.
Contributors CR was the physician under whom the outpatient department was conducted where the patient attended. He had a major role in conception of the idea of writing, editing, formatting and uploading the manuscript. VAT, RG and RP were responsible for obtaining the consent of the patient, taking photographs of the patient, writing the first draft and collecting references.

Competing interests None.

Patient consent Obtained.

Provenance and peer review Not commissioned; externally peer reviewed.

\section{REFERENCES}

1 Spector RH. The pupils. In: Walker HK, Hall WD, Hurst JW, eds. Clinical methods: the history, physical, and laboratory examinations. chap 58, 3rd edn. Boston: Butterworths, 1990.

2 "Joe" Benjamin William J. Optical phenomena of contact lenses. In: Bennett ES, Weissman BA, eds. Clinical contact lens practice. chap 7A, 3rd edn. Philadelphia: Lippincott Williams \& Wilkins, 2004:119.

3 Atkinson CS, Brodsky MC, Hiles DA, et al. Idiopathic tractional corectopia. J Pediatr Ophthalmol Strabismus 1994;31:387-90.

Copyright 2014 BMJ Publishing Group. All rights reserved. For permission to reuse any of this content visit http://group.bmj.com/group/rights-licensing/permissions.

BMJ Case Report Fellows may re-use this article for personal use and teaching without any further permission.

Become a Fellow of BMJ Case Reports today and you can:

- Submit as many cases as you like

- Enjoy fast sympathetic peer review and rapid publication of accepted articles

- Access all the published articles

- Re-use any of the published material for personal use and teaching without further permission

For information on Institutional Fellowships contact consortiasales@bmjgroup.com

Visit casereports.bmj.com for more articles like this and to become a Fellow 